\title{
Boyun ağrısında gizli tehlike: Karotidini
}

\author{
Barış Türk1, Feride Aydan Öztürk², İrfan Çelebi ${ }^{3}$, Hacer Şebnem Türk ${ }^{4}$
}

\begin{abstract}
ÖZET:
Boyun ağrısında gizli tehlike: Karotidini

Karotidini, karotis bifurkasyon bölgesinin palpasyon sırasında tek taraflı hassasiyetiyle karakterize bir boyun ağrısı sendromudur. Bu sendromun doğru teşhisi için ayırıcı tanının oldukça dikkatli yapıması gerekir. Karotidini için ayırıcı tanıda, Takayasu ve temporal arteriti gibi büyük damar vaskülitleri, arterioskleroz, tromboz, fibromuskular displazi, diseksiyon ve anevrizmanın yanı sıra non-vasküler hastalıklar; lenfödem, siyaloadenit, tiroidit, peritonsiller abse veya boyun neoplazileri sayılabilir. Takayasu arteriti, etiyolojisi bilinmeyen aort ve ana dallarını tutan, nadir görülen kronik sistemik granülomatöz inflamatuar bir hastalıktır. Karotidini, Takayasu arteriti ve diğer büyük damar vaskülitlerinin klinik bir işareti olabilir. Bu çalışmada, idiopatik ve Takayasu arteritli olmak üzere iki karotidini olgusunun ultrasonografik ve manyetik rezonans bulgularını sunduk.
\end{abstract}

Anahtar kelimeler: Karotidini, boyun ağrısı, takayasu arteriti

\section{ABSTRACT:}

Hidden danger in neck pain: Carotidynia

Carotidynia is a neck pain syndrome, characterized by unilateral tenderness to palpation over the carotid bifurcation area. The differential diagnosis for carotidynia should be done carefully for the proper identification of this syndrome. The differential diagnosis for carotidynia includes large-vessel vasculitides such as Takayasu's and temporal arteritis, arteriosclerosis, thrombosis, fibromuscular dysplasia, dissection and aneurysm, as well as other non-vascular diseases such as lymphoedemas, sialodenitis, thyroiditis, peritonsiller abse or neck neoplasms. Takayasu's arteritis is a rare chronic systemic granulomatous inflammatory disease that affect the aorta and its major branchs with unknown etiology. Carotidynia may be a clinical sign of Takayasu arteritis and other large vessel vasculitides. In this study, we report ultrasonographic and magnetic resonance imaging findings in two patients with idiopatic carotidynia and Takayasu arteritis as a cause of carotidynia.

Key words: Carotidynia, neck pain, Takayasu arteritis

Ş.E.E.A.H. Tıp Bülteni 2013;47(1):30-34
${ }^{1}$ Uzm. Dr., Kağıthane Devlet Hastanesi, Radyoloji Kliniği, İstanbul-Türkiye ¿Uzm. Dr., Kağıthane Devlet Hastanesi Kulak Burun Boğaz Klinği, İstanbul-Türkiye ${ }^{3} U z m$. Dr., Şişli Etfal Eğitim Ve Araştırma Hastanesi Radyoloji Kliniği, İstanbul-Türkiye ${ }^{4} U z m$. Dr., Şişli Etfal Eğitim Ve Araştırma Hastanesi, 1. Anesteziyoloji Ve Reanimasyon Kliniği, İstanbul-Türkiye

Yazışma Adresi / Address reprint requests to: Uzm. Dr. Barış Türk, Kağıthane Devlet Hastanesi Radyoloji Kliniği, İstanbul-Türkiye

Telefon / Phone: +90-212-280-2222/1362

Faks / Fax: +90-212-280-0500

E-posta / E-mail:

drturkbaris@hotmail.com

Geliş tarihi / Date of receipt: 8 Mayıs 2012 / May 8, 2012

Kabul tarihi / Date of acceptance: 11 Kasım 2012 / November 11, 2012

\section{Gíriş VE AMAÇ}

Karotidini, karotid bifurkasyon düzeyine bası ile hassasiyetin gözlendiği, nadir görülen tek taraflı boyun ağrısı sendromudur. Ağrıyı oluşturan temel mekanizma sinir trasesinin bulunduğu karotid kılıfının idiopatik inflamasyonudur. Ayırıcı tanıda, Takayasu ve temporal arteriti, tromboz, diseksiyon ve anevrizma gibi vasküler hastalıklarla; lenfödem, siyaloadenit, peritonsiller abse ve boyun neoplazileri sayılabilir. Karotidini, Takayasu Arteriti (TA) gibi büyük damar vaskülitlerinde inflamatuar proçesin karotid kılıfını etkilemesiyle de görülebilir. TA, aort ve aortun ana dallarını tutan nadir gözlenen tıkayıcı bir damar vaskülitidir.Yıllık sıklığı 2.6/milyon, yay- gınlığı ise 2.6-6.4/milyondur. Geç dönemde, tutulan damarın lümenindeki darlığa bağlı olarak beslediği organa ilişkin iskemik belirtiler gözlenir. İskemi gelişen organa bağlı morbidite oranı yüksekliği erken tanının önemini arttırmaktadır. Karotid kılıfının inflamasyonuna ve arterite bağlı değişiklikler ultrasonografi (US) ve Manyetik Rezonans (MR) görüntüleme ile rahatlıkla gösterilmektedir. Görüntülemede US bulguları çoğu defa tanı koydurucudur. Kapsamlı tarama için yağ baskılı T2 ağırlıklı (T2A) ve post-kontrast yağ baskılı T1 ağırlıklı (T1A) MR sekansları yeterlidir. Ayrıca boyun ağrısında US ve MR görüntüleme ile vasküler patolojiler yanında boyunda yumuşak doku kaynaklı olabilecek ilave patolojiler de saptanabilmektedir. 


\section{OLGU SUNUMU}

41 yaşındaki erkek olgu Kulak Burun Boğaz bölümüne tek taraflı boyun ağrısı şikayeti ile başvurmuş. Yapılan fizik muayenede boyunun sağ yarısında lokal hassasiyet olduğu tespit edilmiş. Ele gelen kitle saptanmamış. Boyun US isteğiyle Radyoloji ünitesine başvurmuş.

25 yaşında bayan olgunun anal fissür nedeniyle operasyonu planlanmış. Preoperatif anestezi değerlendirilmesinde, anamnezinde sol kolda uyuşma, sol boyun ağrısı ve ara ara baş dönmesi şikayeti olduğu öğrenilmiş. Yapılan fizik muayenede sol kolda tansiyon arteryelin ölçülememesi üzerine sağ koldan ölçümü tekrarlanmış. Sağ kol tansiyon arteryel değe- ri 130/90 mmHg bulunmuş. Bunun üzerine Renkli Doppler US isteminde bulunulmuş.

Olguların yapılan US incelemelerinde, boyun hassasiyetinin olduğu bölgelerin derin planında karotid arter bulbus segmentleri görüldü. Bulbus duvarı dışına doğru eksantrik tarzda uzanan hipoekoik duvar kalınlaşmaları izlendi. Erkek olguda kalınlık artışı karotid arter bifurkasyonundan internal karotid arter proksimaline aralık vermeden uzanıyordu ve lümende anlamlı darlık oluşturmamaktaydı (Resim 1). Diğer karotid arter segmentlerine yönelik yapılan incelemelerde benzer bir kalınlaşma veya plak formasyonu saptanmadı. Bayan olguda ilave olarak sol ana karotid arterde bifurkasyonuna kadar, sağ ana karotid arter başlangıcından itibaren kısa bir segment

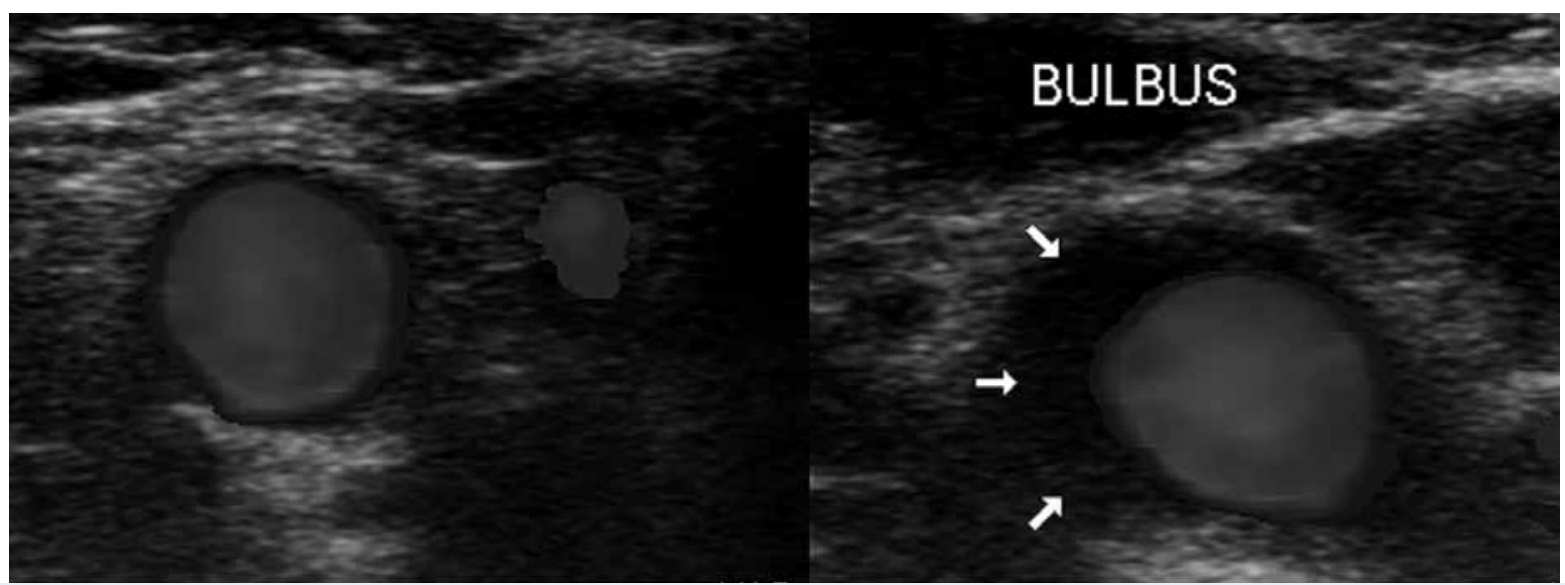

Resim 1: Sağ karotid arter prebulber alanda damar duvarı doğal kalınlıkta izlenmekte. Karotid arter bulbus segmentinde damar duvarında ekzantrik hipoekoik kalınlaşma (beyaz oklar).

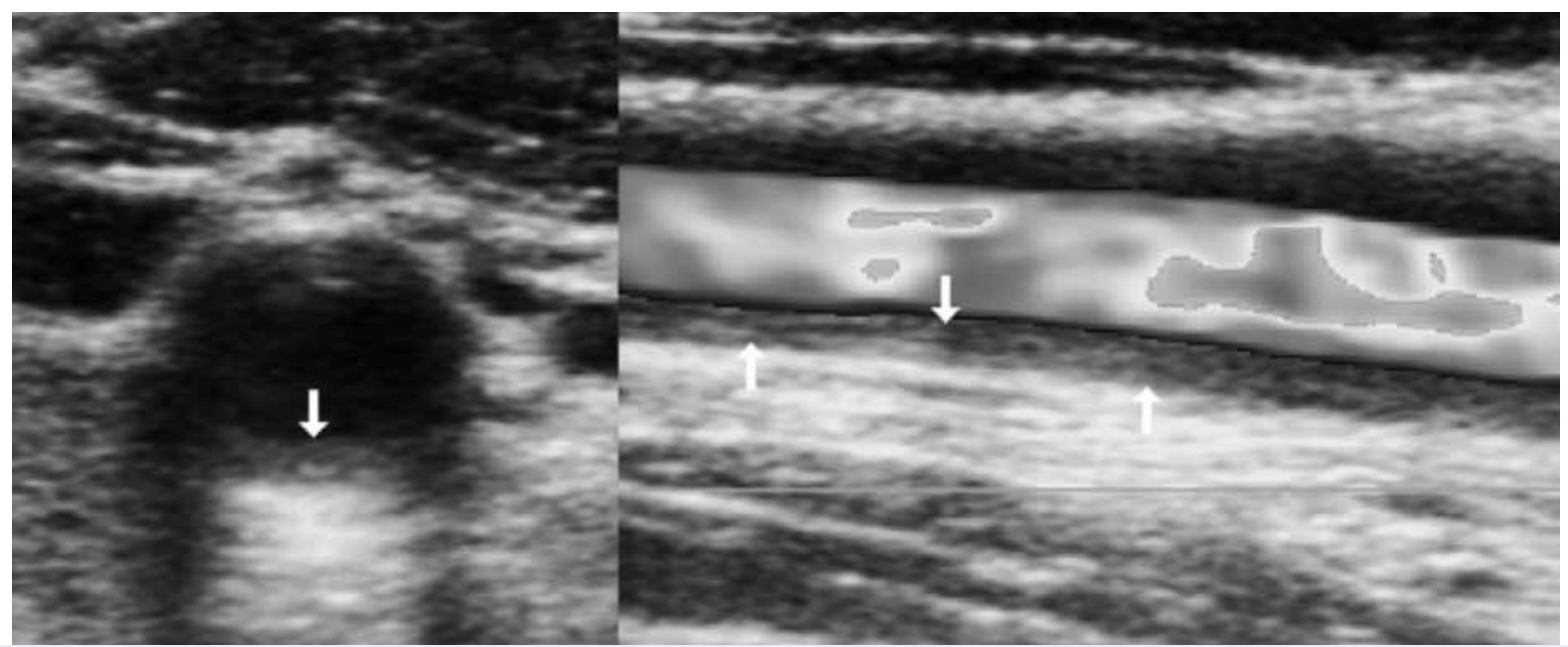

Resim 2: Sol ana karotid arter endotelyal yüzeyde konsantrik tarzda düzgün konturlu homojen isoekoik kalınlaşma (beyaz oklar). 
3. a)
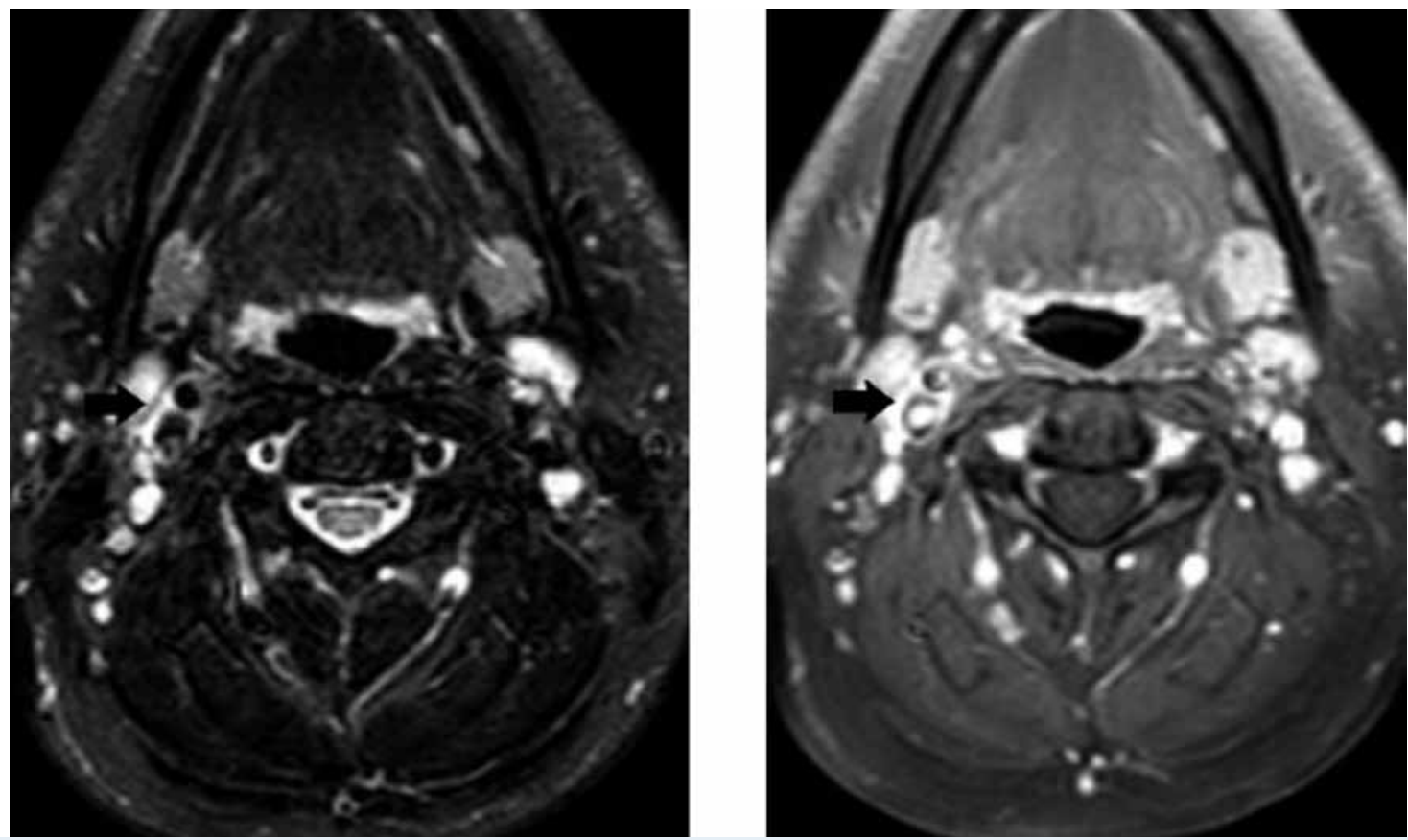

3. b)

Resim 3: a) Aksiyel planda yağ baskılı T2 ağırlıklı MR kesitinde internal karotid arter proksimalinde kalınlaşma ve inflamasyona bağlı ödem b)Yağ baskılı post-kontrast T1 ağırlıklı MR kesitinde internal karotid arter duvarında kalınlaşma ve inflamatuar duvarın kontrast tutulumu.

boyunca endotelyal yüzlerde halkasal tarzda isoekoik kalınlaşmalar izlendi (Resim 2). Ayrıca sol üst ekstremite arterlerine yönelik yapılan incelemede de sol aksiller arterde lüminal darlığa neden olan benzer görünümde kalınlaşmalar gözlendi. Darlığın distalinde kalan arteryel yapılar doğal izlenmekle birlikte spektral analizinde post-stenotik baskılanmış akım mevcuttu. Kalınlaşmaların lümene doğru büyümesi ilave arteriti düşündürdü.

Erkek olguya ilave boyun MR ve manyetik rezonans anjiografik (MRA) inceleme, bayan olguya tanıyı doğrulamak ve diğer arteryel yapıların incelenmesi amacıyla boyun MR inceleme ile kranial, boyun, toraks, batın MRA incelemeler yapıldı. US incelemelerde karotid kılıfınının kalınlaştığı bölgelerde, T2A MR incelemelerde intensite artışı mevcuttu ve postkontrast yağ baskılı T1A incelemelerde aynı karotid segmentleri duvarları çevresinde homojen kontrastlanma izlendi (Resim 3). Bayan olguda MRA incelemede sol karotid arter bifurkasyona kadar, sağ karotid arter ve sol vertebral arter çıkımında lüminal darlıklar gözlendi (Resim 4). İlave olarak sol aksiller arterde, infrarenal düzeyde abdominal aortada da lüminal daralmalar mevcuttu. Bu bulgular ışığında

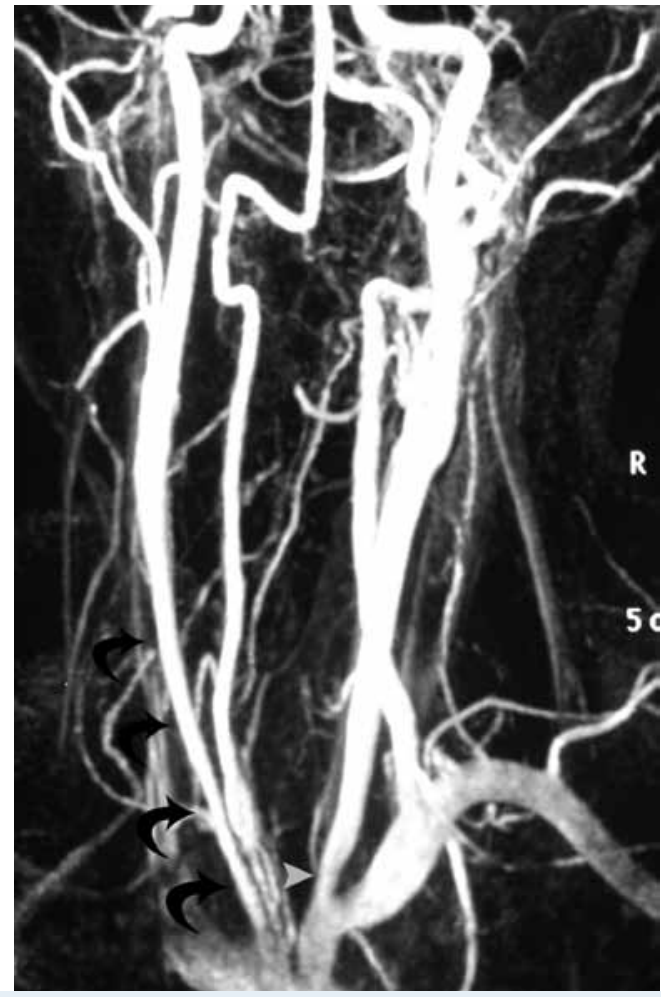

Resim 4: Boyun MRA incelemede sol karotid arter başlangıcından bifurkasyona kadar (kıvrımlı oklar) ve sağ karotid arter başlangıcında (okbaşı) lüminal darlıklar. 
TA tanısı kondu.

Olgulara tedavi olarak non-steroid antiinflamatuar verildi. TA tanısı konan olguya prednizolon, metotreksat tedavisi eklendi. Olguların 3 hafta sonundaki kontrol US, MR tetkiklerinde etkilenen karotid arter duvarındaki eksantrik kalınlaşmaların tamamen regresyon gösterdiği izlendi. TA tanısı konan olgumuzun tedavi süreci halen devam etmektedir ve tariflenen arteryel bölgelerdeki lüminal daralmaları devam etmektedir.

\section{TARTIŞMA}

Karotidini, vasküler boyun ağrısının nadir bir nedenidir ve karotid arter bifurkasyonu düzeyinde hassasiyet ve ağrı ile karakterize unilateral boyun ağrısı sendromudur (1). İdiopatik bir inflamasyon olarak kabul edilen bu patoloji, antiinflamatuar ilaç tedavisiyle veya spontan olarak düzelir. Ayırıcı tanıda, Takayasu ve temporal arteriti, arterioskleroz, tromboz, fibromuskular displazi, diseksiyon ve anevrizma gibi vasküler hastalıklarla; lenfödem, siyaloadenit, tiroidit, peritonsiller abse ve boyun neoplazileri sayılabilir (2).

Karotid arterlerde sinir traseleri adventisya ve media tabakaları arasında bulunmaktadır ve karotidini tanısında ağrı ve hassasiyetin temel nedeni adventisya tabakasının tutulumudur. Upton ve arkadaşları, karotid endarterektomisi uygulanan bir olguda adventisya çevresinin kalın ve düzensiz olduğunu tespit edip, biyopsi almışlardır. Gram boyamada ve kültür sonucunda üreme olmadığını gözlemlemişler, granüloma ve abse tespit etmemişlerdir. Ayrıca vaskülitlerdeki damar çevresi inflamasyonunda gözlenen dev hücrelere de rastlamamışlardır. Bu alanlarda non-enfeksiyoz kronik inflamasyonu gösteren lenfoblastlar, birkaç polimorf nükleer hücre ve mast hücreleri izlemişlerdir. Bu bulgular idiyopatik karotidininin oluşum mekanizmasını açıklamaktadır (3). TA gibi damar vaskülitlerinde de karotidini gelişim mekanizması, inflamatuar proçesin media tabakasını etkilemesi ve sonrasında bu alandan vaso vasorumlar yoluyla adventisya tabakasına geçişiyle açıklanır.

TA, sıklıkla genç kadınlarda görülen, etiyolojisi bilinmeyen, fakat otoimmun kabul edilen, daha çok aorta, aortik arkın dalları ve pulmoner arterleri tutan, nadir görülen sistemik granülomatöz bir enflamasyondur (4-5). Hastalığın erken döneminde endotelyumda plazma hücreleri, lenfositler ve dev hücre infiltrasyonu görülür. Geç döneminde ise media ve adventisya tabakalarında fibrozis meydana gelir ve bunun sonucunda lümende ileri derecede darlık, oklüzyon ve anevrizmal dilatasyon gelişebilir. Etkilenen damarın beslediği organa ait iskemik belirtiler gözlenir. TA'da iskemi gelişen organa bağlı olarak morbidite oranı yüksektir. TA'lı hastaların \%32 sinde karotodini rapor edilmiştir (6). Bu nedenle karotidini düşünülen olgularda TA gibi damar vaskülitleri akla gelmelidir. TA'da konvansiyonel anjiografi tanı ve değerlendirmede altın standarttır (7). Ancak invaziv olması, morbidite ve mortalite riskleri olduğundan noninvaziv MR, MRA ve BT anjiografi alternatif modalitelerdir. Özellikle MR incelemeleri damar duvar kalınlığında artışı, luminal daralmayı ve dilatasyonu, aktif inflamasyon fazında kalınlaşmış damar duvarında kontrast tutulumunu göstermesi açısından önemlidir (4).

Tek taraflı, hareketle ortaya çıkan, lokalize boyun ağrısı ile başvuran hastalarda ilk inceleme yöntemi olarak US kullanılabilir. Gerçek zamanlı bir inceleme tekniği olması nedeniyle de bu bölgede ağrıya neden olabilecek diğer faktörler US ile dışlanabilmektedir (8). US incelemelerde boynun ağrılı ve hassas olan bölgelerine uyan alanda karotid arter duvarlarında kalınlaşma ve homojen hipoekoik görünüm tesbit edilmiştir. Özellikle karotid kılıfının dışına doğru olan kalınlaşmalar ve bası ile hassasiyetin bulunması karotidini tanısını ön planda düşündürmüştür. Erkek olguda diğer karotid arter segmentlerinde benzer bir kalınlaşma ya da plak formasyonu bulunmaması, ateroskleroz gibi yaygın patolojiden çok öncelikle lokalize bir hastalığı işaret etmiş̧ir. Bayan olgumuzda her iki karotid segmentlerinde fokal alanlarda endotelyal yüzey boyunca halkasal tarzda isoekoik kalınlaşmalar izlenmiştir. Benzer görünümün karotid segmentleri dışında başka arteryel noktalarda olması ve kalınlaşmanın karotid kılıfı dışından ziyade lümene doğru büyümesi ilave arterit varlığını düşündürmüştür.

Karotidinin klinik olarak tespitinin zor olması, karotid arterlerden sıklıkla biyopsi alınmaması nedeniyle histolojik olarak gösterilememesinden dolayı 
karotidini tanısında görüntüleme yöntemleri önemlidir. Ayrıca gerek vasküler kaynaklı, gerekse boyunda yumuşak doku kaynaklı olabilecek patolojileri göstermesi amacıyla ileri görüntüleme yöntemi olarak MR ve BT çekimleri uygundur. 2001 yılında Buetow ve Delano karotid kılıfının yumuşak doku infiltrasyonunu BT ve MR ile karşılaştırmışlardır (9). BT incelemedeki karotid kılıfı çevresindeki yumuşak dokunun post-kontrast incelemelerde homojen kontrastlandığını gözlemlemişlerdir. MR incelemede post-kontrast T1A imajlarda karotid kılıfındaki kalınlaşmış dokuda homojen kontrastlanma ve T2A imajlarda aynı lokalizasyonda sinyal intensite artışı göstermişlerdir. BT ve MR incelemelerinde benzer sonuçlar bulmuşlardır. Ayrıca 2003 yılında Grunebaum ve arkadaşları yaptıkları çalışmada, karotidini düşünülen olguların değerlendirmesinde MR ve MRA birincil tanı yöntemi olarak kullanılmalıdır sonucuna varmışlardır (10). Kontrastlı boyun MR incelemelerinde kontrast tutulum özelliği kalınlaşmanın enflamatuar yapısını ortaya koyarken lümende anlamlı darlık ya da kontur düzensizliği olmaması kontrast tutulumunun karotid kılıfının adventisya tabakasında olduğunu göster-

\section{KAYNAKLAR}

1. Hill LM, Hasting G. Carotidynia: a pain syndrome. J Fam Pract 1994;39(1):71-5.

2. Da Rocha AJ, Tokura EH, Romualdo AP, Fatio M, Gama HP. Imaging contribution for the diagnosis of carotidynia. J Headache Pain 2009;10(2):125-7.

3. Upton PD, Smith JG, Charnock DR. Histologic confirmation of carotidynia. Otolaryngol Head Neck Surg 2003;129(4):443-4.

4. Andrews J, Mason JC. Takayasu's arteritis--recent advances in imaging offer promise. Rheumatology (Oxford) 2007 Jan;46(1):615.

5. Yıldırım E, Tahmaz M, Kumbasar A, Ergen AK, Ertem DH, Altunkaynak Y. Senkopun Nadir Bir Nedeni: Takayasu Arteritine Bağlı Gelişen Subklavian Çalma Sendromu. Düşünen Adam Psikiyatri ve Nörolojik Bilimler Dergisi 2011;24(4):345-8. doi:10.5350/DAJPN2011240411.

6. Kerr GS, Hallahan CW, Giordano J, Leavitt RY, Fauci AS, Rottem M, Hoffman GS. Takayasu arteritis. Ann Intern Med 1994;120(11):919-29. mektedir (11-12). Özelikle damar duvarına yönelik yapılan yağ baskılı T2A ve post-kontrast yağ baskılı T1A sekanslar değerlidir. Mevcut literatürlerde, karotidini tanısı almış tüm olguların post-kontrast T1A çekimlerinde karotid kılıfının kontrastlandığı bildirilmiştir (13-14). Ayrıca MR inceleme kontrast tutulum özelliği ile enflamatuar duvar kalınlaşmalarını, US incelemede karıştırılabilecek fibrofatty plak formasyonundan ayırtedebilir. Olgularımızda çekilen kontrastlı boyun MR incelemelerinde etkilenen karotid segmentlerinin duvar ve kılıfında yumuşak doku kalınlaşması ve kontrast tutulumu gösterilmiştir.

Sonuç olarak; tek taraflı boyun ağrısı ile başvuran olgularda karotidini akla gelmelidir. Karotidini tanısında asıl önemli nokta TA gibi vaskülitlerle olan birlikteliğidir. Bizim olgularımızda da görüldüğü gibi bu olgular, farklı kliniklerde karşımıza çıkabilmektedir. Basit bir fizik muayene TA'dan şüphelenilmesini sağlamaktadır. Görüntülemede US bulguları çoğu defa tanı koydurucudur. Kapsamlı tarama için yağ baskılı T2A ve post-kontrast yağ baskılı T1A MR sekansları yeterlidir. Bu sayede erken tedavi ile morbiditenin önüne geçilebilmektedir.

7. Kisin EY, Merkel PA. Diagnostic imaging in Takayasu arteritis. Curr Opin Rheumatology 2004;16(1):31-7.

8. Stanbro M, Gray BH, Kellicut DC. Carotidynia: revisiting an unfamiliar entity. Ann VasC Surg 2011 Nov;25(8):1144-53. doi:10.1016/j.avsg.2011.06.006.

9. Buetow M, Delano M. Carotidynia. American Journal Roentgenology 2001;177(4):947.

10. Grunebaum LD, Pribitkin EA, Rao V. MRI findings in carotidynia. Internet J Otorhinolaryngol 2003;2(1):2

11. Duncan I, Fourie P, Spangenberg A, Fourie $P$, Le Stolp DC. Imaging of carotidynia. S Afr Med J 2004 Dec;94(12):957-9.

12. Castrillo Sanz A, Mendoza Rodríguez A, Gil Polo C, Gutiérrez Ríos R. Symptomatic carotidynia: neck pain of vascular origin. Neurologia 2011 Jun;26(5):310. doi:10.1016/j.nrl.2010.12.015.

13. Farage L, Motta AC, Goldenberg D, Aygün N, Yousem DMI. Idiopathic inflammatory pseudotumor of the carotid sheath. Arq Neuropsiquiatr 2007;65(4B):1241-4.

14. T.C. Lee, R. Swartz, R. MCEvilly. CTA, MR, and MRA imaging of carotidynia: case report. Can J Neurol Sci 2009;36(3):373-5. 